\title{
Embryonal Rhabdomyosarcoma of Middle Ear and Temporal Bone: A Rare Case Report
}

\author{
Gvs Rao $^{1 *}$, Laxminath Ganji ${ }^{1}$, Shree Rao ${ }^{1}$, Chaitanya Rao', Raja Sekhar ${ }^{2}$ \\ ${ }^{1}$ Dr Raos ENT Superspeciality International Hospital, Hyderabad, India \\ ${ }^{2}$ National Pathology Lab, Hyderabad, India \\ Email: ^dr_gvsrao@yahoo.com
}

How to cite this paper: Rao, G., Ganji, L. Rao, S., Rao, C. and Sekhar, R. (2021) Embryonal Rhabdomyosarcoma of Middle Ear and Temporal Bone: A Rare Case Report. International Journal of Otolaryngology and Head \& Neck Surgery, 10, 426-432. https://doi.org/10.4236/ijohns.2021.105039

Received: August 10, 2021

Accepted: September 20, 2021

Published: September 23, 2021

Copyright (c) 2021 by author(s) and Scientific Research Publishing Inc. This work is licensed under the Creative Commons Attribution International License (CC BY 4.0).

http://creativecommons.org/licenses/by/4.0/

\begin{abstract}
Introduction: Rhabdomyosarcoma accounts for up to $60 \%$ of childhood soft tissue sarcoma, occurring mostly in the head and neck region but rarely in the ear and temporal areas. Case Report: A 4-year-old boy came to our hospital due to a purulent discharge, bleeding from his left ear. Also seen mass in the left ear along with facial weakness and diplopia. After histopathologic evaluation, it was diagnosed as embryonal rhabdomyosarcoma. Conclusion: Rhabdomyosarcoma should be kept in mind as a differential diagnosis in all children presenting with otitis media with mastoiditis. Biopsy should be considered who are not responding to medications and those worsening condition.
\end{abstract}

\section{Keywords}

Rhabdomyosarcoma (RMS), Embryonal, Temporal Bone, Petrositis

\section{Introduction}

Rhabdomyosarcoma is the most common soft tissue malignancy found in children less than 5 years of age [1]. Rhabdomyosarcoma is a sarcoma arising from skeletal muscle. It has been divided into 4 categories: embryonal, botryoid, pleomorphic and alveolar [2]. Embryonal rhabdomyosarcoma of the middle ear was first described by Soderberg [3] in 1932. Rhabdomyosarcomas are highly aggressive locally destructive, malignant neoplasm of the soft tissue [4]. The most common site that involved by rhabdomyosarcoma is orbit (about one-third of cases). After that, in decreasing order, rhabdomyosarcoma affects oral cavity and pharynx (29\%), the face and neck region (24\%) [4], rarely ear and temporal bone [5]. Rhabdomyosarcoma frequently looks like polypoid mass on examination, so easily misdiagnosed as aural polyp and therefore, advanced disease with meningeal involvement is common at the time of diagnosis [6]. 
We present this case to highlight the clinical presentation of embryonal rhabdomyosarcoma in a child as it mimics ASOM with complications. Even CT scan could not help to attain early accurate diagnosis. Only histopathology helps in final diagnosis.

\section{Case Presentation}

A 4-year-old boy came to our hospital with complaints of Ear ache, purulent discharge, bleeding from left ear since 1 month. Also noticed a mass in left ear since 20 days. He developed left facial paralysis since 1week and diplopia since 3 days. He was treated with antibiotics for 3 weeks elsewhere with no response instead his symptoms got worse after which he was asked to visit a higher centre. On physical examination, there was a polypoid, reddish and fragile mass that filled the external ear canal in the left side, facial nerve palsy (Figure 1(a)), Diplopia (Figure 1(b)) and there was foul smelling discharge from the ear canal. Biochemistry tests were normal. In CT Temporal Bone scan, soft tissue density was present in the mastoid and middle ear. The mass involved the external ear and projected from external auditory meatus. Permeative osteolytic destruction of petrous apex, left carotid canal (Figure 2). Reported as left acute otomastoiditis with petrous apicitis. MRI Brain was normal.

Patient was admitted and mastoid exploration done. Multiple polypoidal tissue removed from Eustachian tube recess, middle ear, aditus, antrum and mastoid were sent for histopathological examination. HPE revealed poorly differentiated malignant neoplasm in favour of Embryonal Rhabdomyosarcoma. Immunohistochemistry for Desmin and Myogenin markers came positive confirming the diagnosis (Figure 3).

Post op PET CT scan showed status modified radical mastoidectomy, heterogeneously enhancing soft tissue density lesion in left middle ear eroding the petrous

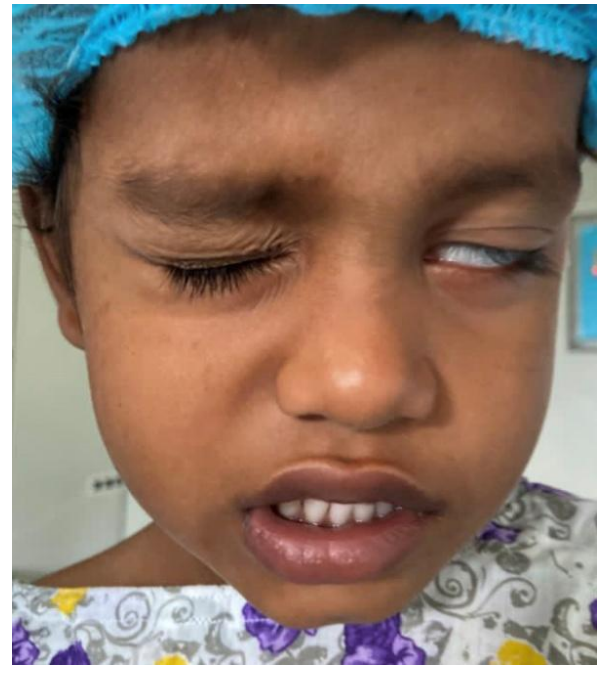

(a)

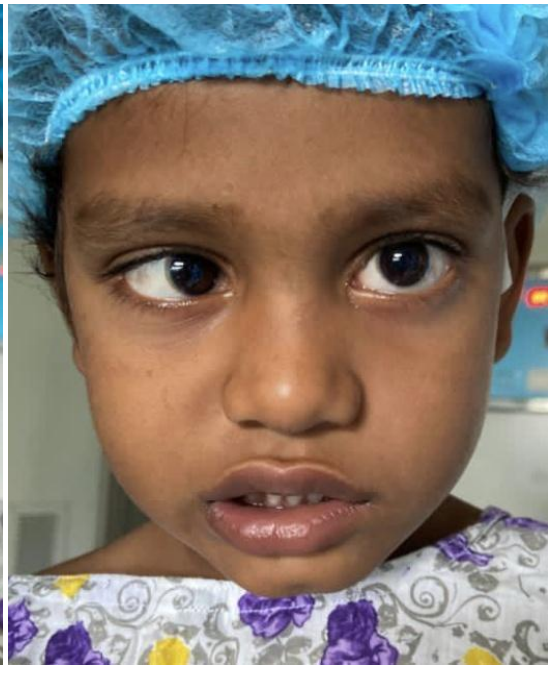

(b)

Figure 1. Clinical pictures. (a) Left facial nerve palsy; (b) Diplopia. 


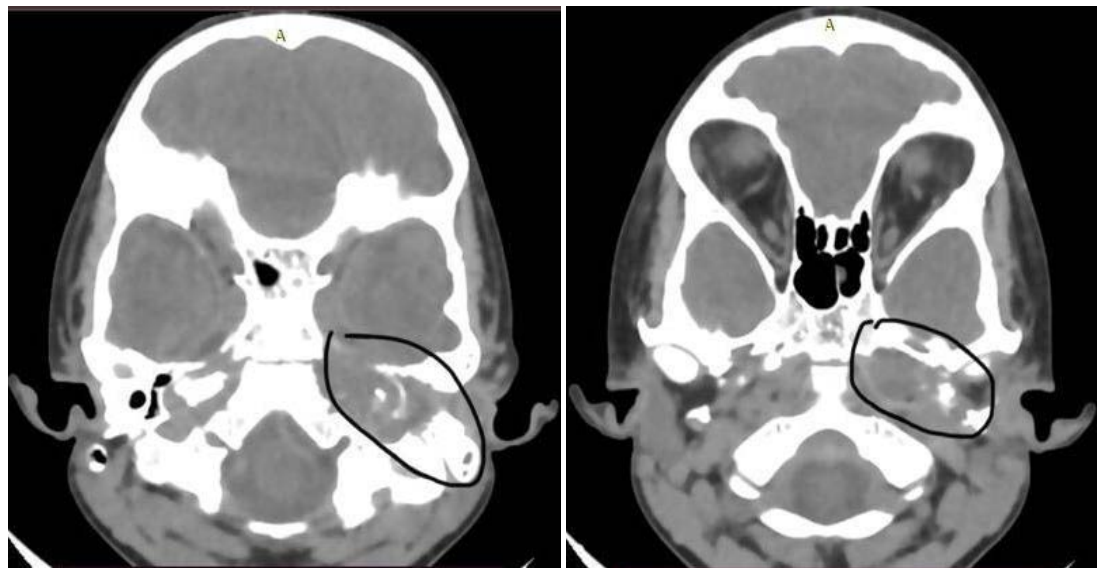

Figure 2. HRCT Temporal bone images. The mass involving external auditory canal, middle ear and mastoid. Permeative destruction of petrous apex and left carotid canal can be seen.

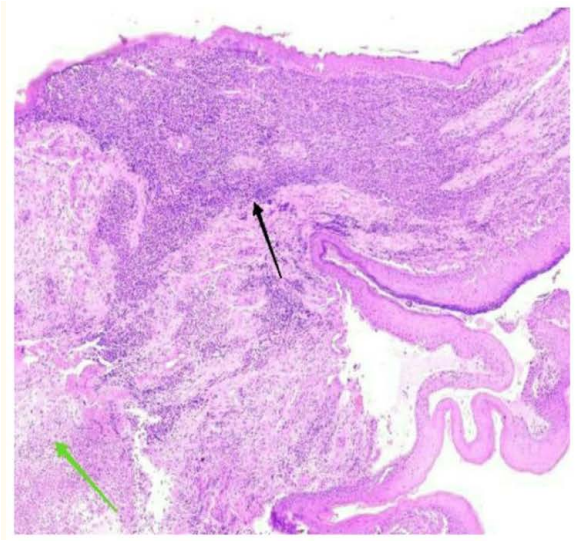

(a)

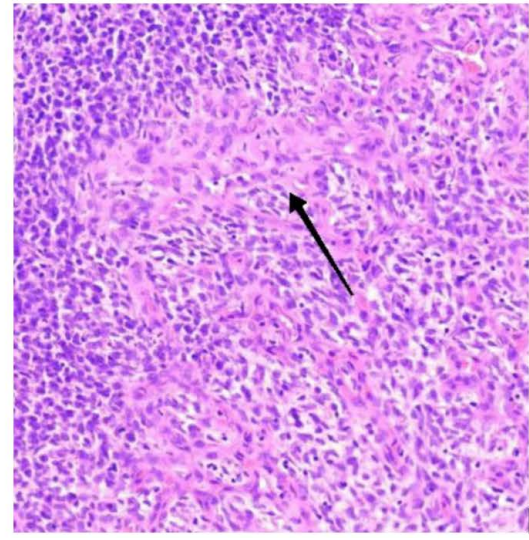

(b)

Figure 3. Histopathology pictures. (a) black arrow-tumor tissue, green arrow-myxoid stroma; (b) Strap cells that look like primitive muscle cells that classically described in Rhabdomyosarcoma are seen in this picture. The cells show a combination of shapes but a spindle or elongated morphology is evident overall.

temporal bone, clivus inferiorly extending into the parapharyngeal space, superiorly there is mild intracranial extension into middle cranial fossa. Final diagnosis was Embryonal Rhabdomyosarcoma of left middle ear (Parameningeal site) Stage III, Group III, Intermediate risk. CSF was negative for malignancy. He has been planned for chemotherapy along with radiotherapy. He received Local RT 50.4 Gy in 28 cycles followed by 40 week VAC chemotherapy (Inj Vincristine $1 \mathrm{mg}+$ Inj Cyclophosphamide $840 \mathrm{mg}+\mathrm{Inj}$ Actinomycin-D $0.7 \mathrm{mg}$ ). He is under follow up with no signs of recurrence for 1year.

\section{Discussion}

Most soft tissue sarcomas in pediatrics are rhabdomyosarcoma (60\%) accounting for about $13 \%$ of all pediatric malignancies [7] [8]. It is considered malignant neoplasia derived from striated muscle arising in any part of the body; however, 
it is more common in regions of the head and neck, genitourinary tract, retroperitoneum and extremities [5]. Approximately 35\% of all pediatric rhabdomyosarcomas occur in the head and neck [4] [9]. Only 7\% of rhabdomyosarcomas arise in the middle ear, and they may begin either in the muscles of the eustachian tube, in the proper middle ear, or from primitive pluripotential mesenchymal rests [1] [10]. This case we confirm its arising in the middle ear cleft based on intraoperative findings but could not locate exact site of origin. Pathologic subtypes of RMS include as follows: embryonal, botryoid, alveolar, pleomorphic, spindle cell and anaplastic variants [11]. The embryonal RMS includes about $60 \%-70 \%$ of RMS cases [12]. Our case is embryonal subtype.

Jaffe et al. reported there is no sex predominance, there does not appear to be a predilection for either right or left ear [13]. In 1966 Potter reported Embryonal Rhabdomyosarcoma affects one ear only, the other being normal [14]. In our case also we found only unilateral disease. Presentation of rhabdomyosarcoma of the ear and temporal bone usually mimics that of the chronic suppurative otitis media that is unresponsive to the usual treatment [15] [16]. In our case we made diagnosis of acute otitis media with mastoiditis with petrocitis with complications. But to our surprise the biopsy report came as Embryonal Rhabdomyosarcoma. The most common presenting symptoms are a triad of otitis media, polypoid mass in the external ear and bloody discharge from the ear [14]. However, progression is fairly fast, and facial nerve palsy is usually present at diagnosis. Involvement of the petrous apex, internal auditory canal, and skull base may lead to other cranial neuropathies [17]. Approximately $30 \%$ of these patients will have neurologic deficits at diagnosis [18]. In our case the patient developed earache, purulent discharge, bleeding, decreased hearing, polypoidal mass in the external ear, facial nerve palsy and diplopia. This is probably the first case to be reported with diplopia (abducens nerve palsy) in rhabdomyosarcoma of middle ear and temporal bone.

Jaffe et al. reported many of the neoplasms present as a result of directextensions through the temporal bone. If the tumor erodes inferiorly, acontiguous neck mass will appear in the area of the mastoid tip. If the neoplasm of the petrous portion of the temporal bone erodes inferiorly, a contiguous parapharyngeal mass will push in the nasopharyngeal or oropharyngeal walls. In one case, the parapharyngeal mass pushed the tonsilmedially; in another case, bulged into the soft palate and the posterior oropharyngeal and nasopharyngeal wall. Intracranial extension (posterior cranialfossa) was manifested in other cases [13]. In our case there was no intracranial or extratemporal extension. But post surgery PET CT showed lesion in left middle ear eroding petrous temporal bone, clivus extending into parapharyngeal space and superiorly into middle cranial fossa.

Local extension is nearly always present at the time of primary diagnosis and treatment. Metastases occur with a very high frequency, by both lymphogenous and hematogenous routes [13]. Enlarged lymph nodes are more likely associated with distant metastasis [15]. Metastasis can be present in up to $30 \%$ of the cases. 
The most common affected sites are the lungs, liver, bones and extremities [15] [19]. This child did not developed any lymph node metastasis or distant metastasis. Routine histopathological examination shows a round cell tumor [11].

Immunohistochemistry is required to differentially diagnose it from other small round cell neoplasms, namely lymphoma (CD20, CD3 positive) and Ewings sarcoma/PNET (CD99 positive) as Rhabdomyosarcoma is negative for these markers and positive for desmin is diagnostic of rhabdomyosarcoma [11]. The staging of RMS depends on the type of RMS (embryonal or alveolar), the TNM stage and the clinical group. According to these three variables, they can be classified as low risk, intermediate risk, high risk groups whose 5 year survival rates are respectively $90 \%, 60 \%-80 \%, 20 \%-40 \%$ [20]. Systemic treatment with chemotherapy and locoregional control with radiotherapy and if needed surgery is helpful [21]. Surgery is not possible in all cases in areas involving vital structures and intracranial extension [6] [22]. Our patient received Local RT (50.4 Gy) over 28 cycles followed by 40 week VAT chemotherapy after surgery. Regular follow up is done to detect any early recurrence.

\section{Conclusion}

In all children, rhabdomyosarcoma should be considered as a differential diagnosis along with otitis media with mastoiditis when not responding to medical treatment especially when there is history of short duration and rapid progression of symptoms. Strong suspicion of RMS should be made when presenting with EAC mass and nerve deficits and HRCT TB showing bony erosions. Mastoid exploration with biopsy is helpful in diagnosis when not responding to medications.

\section{Conflicts of Interest}

The authors declare no conflicts of interest regarding the publication of this paper.

\section{References}

[1] Hasso, A.N., Vignaud, J. and Bird, C.R. (1988) Pathology of the Temporal Bone and Mastoid. In: Newton, T.H., Hasso, A.N. and Dillon, W.P., Eds., Computed Tomography of the Head and Neck, Raven, New York, 5-9.

[2] Horn, R.C. and Enterline, H.T. (1958) Rhabdomyosarcoma: A Clinicopathological Study and Classification of 39 Cases. Cancer, 11, 181-199. https://doi.org/10.1002/1097-0142(195801/02)11:1<181::AID-CNCR2820110130>3. 0.CO;2-I

[3] Soderberg, F. (1932) Rhabdomyome epipharynge ayantenvahi I'Oreille et les Meninges (Fr.). Acta Oto-Laryngologica (Stockholm), 18, 453-459. https://doi.org/10.3109/00016483309132862

[4] Carol, J.M. and Richard, J.H. (2010) Pediatric Head and Neck Malignancies. In: Paul, W.F., Ed., Cummings Otolarymgology Head \& Neck Surgery, Vol. 3, Mosby, Philadelphia, 2835-2849. https://doi.org/10.1016/B978-0-323-05283-2.00201-9

[5] Chao, C.K., Sheen, T.S., Shau, W.Y., Ting, L.L. and Hsu, M.M. (1999) Treatment, 
Outcomes, and Prognostic Factors of Ear Cancer. Journal of the Formosan Medical Association, 98, 314-318.

[6] Abbas, A. and Awan, S. (2005) Rhabdomyosarcoma of the Middle Ear and Mastoid: A Case Report and Review of Literature. Ear, Nose \& Throat Journal, 84, 780. https://doi.org/10.1177/014556130508401214

[7] MacArthur, C.J. and Smith, H.J. (2010) Pediatric Head and Neck Malignancies. In: Flint, W.P., Haughey, H.B., Lund, J.V., Niparko, K.J., Richardson, A.M., Robbins, T.K., et al., Eds., Cummings Otolaryngology Head and Neck Surgery, Mosby Inc., Philadelphia, 2835-2849. https://doi.org/10.1016/B978-0-323-05283-2.00201-9

[8] Carli, M., Gugliemi, M., Sotti, G., Cecchetto, G. and Ninfo, V. (1997) Soft Tissue Sarcoma. In: Pediatric Oncology, Chapman and Hall, London, 380-416.

[9] Goto, T.K., Yoshiura, K., Tanaka, T., et al. (1998) A Follow-Up of Rhabdomyosarcoma of the Infratemporal Fossa Region in Adults Based on the Magnetic Resonance Imaging Findings: Case Reports. Oral Surgery, Oral Medicine, Oral Pathology, Oral Radiology, and Endodontics, 86, 616-625.

https://doi.org/10.1016/S1079-2104(98)90356-0

[10] Batsakis, J.G. (1979) Tumors of the Head and Neck, Clinical and Pathological Considerations. 2nd Edition, Williams \& Wilkins, Baltimore, 280-288.

[11] Parham, D.M. and Ellison, D.A. (2006) Rhabdomyosarcomas in Adults and Children: An Update. Archives of Pathology \& Laboratory Medicine, 130, 1454-1465. https://doi.org/10.5858/2006-130-1454-RIAACA

[12] Wexler, L., Crist, W. and Helman, L. (2002) Rhabdomyosarcoma and the Undifferentiated Sarcomas. In: Pizzo, P.A. and Poplack, D.G., Eds., Principles and Practice of Pediatric Oncology, 4th Edition, Lippincott, Williams and Wilkins, Philadelphia, 939-963.

[13] Jaffe, et al. (1971) Rhabdomyosarcoma of Middle Ear and Mastoid. Cancer, 27, 29-37. https://doi.org/10.1002/1097-0142(197101)27:1<29::AID-CNCR2820270106>3.0.C O;2-L

[14] Potter, G.D. (1966) Embryonal Rhabdomyosarcoma of the Middle in Children. Cancer, 19, 221-226.

https://doi.org/10.1002/1097-0142(196602)19:2<221::AID-CNCR2820190213>3.0.C $\underline{\mathrm{O} ; 2-\mathrm{G}}$

[15] Durve, D.V., Kanegaonkar, R.G., Albert, D. and Levitt, G. (2004) Paediatric Rhabdomyosarcoma of the Ear and Temporal Bone. Clinical Otolaryngology and Allied Sciences, 29, 32-37. https://doi.org/10.1111/j.1365-2273.2004.00764.x

[16] Sbeity, S., Abella, A., Arcand, P., Quintal, M.C. and Saliba, I. (2007) Temporal Bone Rhabdomyosarcoma in Children. International Journal of Pediatric Otorhinolaryngology, 71, 807-814. https://doi.org/10.1016/j.ijporl.2007.02.002

[17] Canalis, R.R. and Gussen, R. (1980) Temporal Bone Findings in Rhabdomyosarcoma with Predominantly Petrous Involvement. Archives of Otolaryngology, 106, 290 293. https://doi.org/10.1001/archotol.1980.00790290042014

[18] Schwartz, R.H., Movassaghi, N. and Marion, E.D. (1980) Rhabdomyosarcoma of the Middle Ear: A Wolf in Sheep's Clothing. Pediatrics, 65, 1131-1133.

[19] Binokay, F., Soyupak, S.K., Inal, M., Celiktas, M., Akgül, E., Aksungur, E., et al. (2003) Primary and Metastatic Rhabdomyosarcoma in the Breast: Report of Two Pediatric Cases. European Journal of Radiology, 48, 282-284.

https://doi.org/10.1016/S0720-048X(03)00041-X

[20] Attakkil, A., Thorawade, V., Jagade, M., Kar, R., Rohe, D., Hanowate, R., Rangaraja, D. and Parelkar, K. (2015) Our Experience with Embryonal Rhabdomyosarcoma 
Presenting as Aural Polyp. International Journal of Otolaryngology and Head \& Neck Surgery, 4, 1-5. https://doi.org/10.4236/ijohns.2015.41001

[21] Ulutin, C., Bakkal, B.H. and Kuzhan, O. (2008) A Cohort Study of Adult Rhabdomyosarcoma: A Single Institution Experience. World Journal of Medical Sciences, 3 , 54-59.

[22] Vishvanatha, B. (2007) Embryonal Rhabdomyosarcoma of the Temporal Bone. Ear, Nose \& Throat Journal, 86, 218-222. https://doi.org/10.1177/014556130708600413 